\title{
Registro de Achatina fulica Bowdich, 1822 (Mollusca, Gastropoda) no Brasil: caramujo hospedeiro intermediário da angiostrongilíase
}

\author{
Occurrence of Achatina fulica Bowdich, 1822 \\ (Mollusca, Gastropoda) in Brazil: \\ intermediate snail host of angiostrongyliasis
}

\author{
Horácio Manuel Santana Teles, Jorge Faria Vaz, Luiz Roberto Fontes e Maria de Fátima \\ Domingos
}

Superintendência de Controle de Endemias. São Paulo, SP - Brasil

\begin{abstract}
Resumo
A introdução de Achatina fulica é assinalada em Itariri, SP, Brasil. Essa espécie de caramujo terrestre foi importada para cultivo, visando à comercialização para consumo humano como "escargot". O encontro de exemplares em vida livre mostra a dispersão de $A$. fulica e, conseqüentemente, o risco de transmissão de Angiostrongylus cantonensis, nematóide parasita do homem e de outros vertebrados. Além disso, o caramujo é uma praga importante da agricultura.
\end{abstract}

Moluscos, parasitologia. Infecções por strongylida, prevenção \& controle.

\begin{abstract}
Achatina fulica, the intermediate snail host of angiostrongyliasis and also an agricultural pest, is being bred in Brazil for human consumption as "escargot". The snail has escaped from its artificial breeding sites and its dispersal in Itariri county, State of S. Paulo, is reported here for the first time. A. fulica is a transmitter of the rat lungworm Angiostrongylus cantonensis, nematode which causes meningoencephalic angiostrongyliasis; the risks of human contamination are commented on.
\end{abstract}

Mollusca, parasitology. Strongylida infections, prevention and control. 
Achatina fulica Bowdich, 1822, é espécie pertencente ao grupo dos moluscos pulmonados terrestres, conhecida como caramujo gigante africano. Adultos dessa espécie possuem conchas com 15 a $20 \mathrm{~cm}$ de altura e 10 a $12 \mathrm{~cm}$ de comprimento ${ }^{3}$. Chegam a pesar 200 g. A Figura mostra exemplar coletado em abril de 1996, em terreno de escola rural localizada às margens da Rodovia Pe. Manuel da Nóbrega (SP$165)$, Município de Itariri $\left(24^{\circ} 17^{\prime} 25^{\prime \prime} \mathrm{S}, 4^{\circ} 10^{\prime} 38^{\prime \prime} \mathrm{W}\right)$, Estado de São Paulo, região da bacia do Rio Ribeira de Iguape, parte de lote de 8 exemplares em cultivo no Laboratório de Malacologia da Superintendência de Controle de Endemias (SUCEN), provenientes da horta escolar. Na região existem produtores de "escargots", que importaram A. fulica para esta atividade comercial.

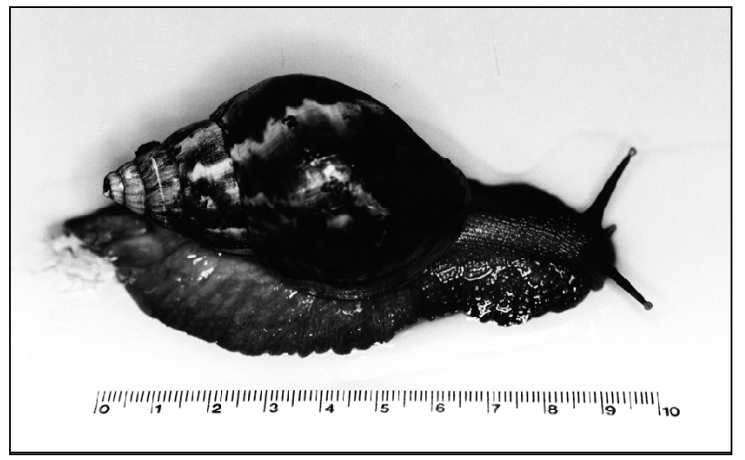

Figura - Exemplar de Achatina fulica procedente do Município de Itariri, Estado de São Paulo, Brasil $(10 \mathrm{~cm})$. Figure - Specimen of Achatina fulica from Itariri county, State of S. Paulo, Brazil $(10 \mathrm{~cm})$.

A introdução de A. fulica no continente americano iniciou-se pelo Havaí, nos idos de 1939, tendo alcançado a Califórnia ao fim da Segunda Guerra Mundial; foi registrada na Flórida no início da década de 70. Nos inúmeros países em que se estabeleceu, A. fulica promoveu a devastação de plantações de banana, mamão, amendoim, café, cítricos e outras, bem como a destruição de grãos armazenados, de jardins e de hortas domésticas. Nos EUA e Austrália foi considerada praga agrícola, exigindo grandes esforços para o controle e erradicação nas áreas invadidas. Em outros países, como Índia, Madagascar e do Sudeste asiático, a espécie permanece presente ${ }^{3}$.

$\mathrm{O}$ encontro de $A$. fulica em vida livre é importante por se tratar de espécie envolvida na transmissão de Angiostrongylus cantonensis (Chen, 1935), nemátodo causador da angiostrongilíase meningoencefálica no homem, doença também denominada meningite (ou meningoencefalite) eosinofílica ${ }^{7}$. O parasita aloja-se no sistema nervoso central com extrema gra- vidade e conquanto apenas conhecido há pouco mais de duas décadas, já foi reportado em diversas regiões geográficas: ilhas do Pacífico (Havaí, Tahiti, Célebes e outras), Sudeste asiático (Vietnã, Tailândia, Sumatra, Malásia, Indonésia, Taiwan e Filipinas), Austrália, Japão e Madagascar ${ }^{2,7,11}$. No início da década de 80, o verme foi encontrado em ratazanas na área urbana da capital de Cuba, em locais com casos de meningite eosinofílica humana atribuídos a $A$. cantonensis (porém sem confirmação parasitológica) ${ }^{1}$. Do ciclo de A. cantonensis participam como hospedeiros intermediários, além de A. fulica, caramujos outros, como Bradybaena similaris Férussac, 1821 e Subulina octona Bruguière, 1789, além de lesmas dos gêneros Veronicella, Limax e Deroceras ${ }^{7}$. Até mesmo o prosobrânquio dulcícola Ampullarius canaliculatus (Lamarck, 1822) é anotado como hospedeiro intermediário ${ }^{9}$. Porém, a susceptibilidade de A. fulica ao parasita, bem como a produção de larvas do nemátodo, é superior a dos demais moluscos ${ }^{10}$.

A angiostrongilíase meningoencefálica apresenta clínica muito variável. Embora poucas vezes fatal, os sintomas podem se arrastar por meses, e além disso ocorrem casos de lesões oculares permanentes ${ }^{11}$. Parece ser contraída pelo homem através da ingestão de larvas de terceiro estádio (L3) de $A$. cantonensis, ou de moluscos infectados pelo verme ${ }^{7}$. Como as larvas são encontradas no muco produzido pelo molusco, e porque eles são ávidos por verduras, legumes e frutas como fonte alimentar, é provável que o consumo humano desses vegetais seja a maneira mais comum de aquisição do parasita. No laboratório da SUCEN, a dieta de A. fulica é complementada por farelo de milho e outros grãos.

O conhecimento do ciclo vital de Angiostrongylus, apesar de incompleto, mostra uma complexidade de situações ${ }^{8}$ nas quais o homem provavelmente aparece como hospedeiro eventual. O molusco é o hospedeiro intermediário e pequenos roedores urbanos e silvestres são os hospedeiros definitivos e reservatórios da verminose. Grande número de outras espécies de moluscos são experimentalmente susceptíveis à infecção pelo nematóide.

No contexto epidemiológico atual, a angiostrongilíase meningoencefálica permanece ausente na área continental americana. Já a outra forma da doença, caracterizada pelo comprometimento de órgãos abdominais, causada por Angiostrongylus costaricensis (Morera e Céspedes, 1971) é encontrada dos EUA ao Norte da Argentina. No Brasil, a forma abdominal incide nos Estados do Rio Grande do Sul, Santa Catarina, Paraná, São Paulo e no Distrito Federal, e tem por hospedeiro intermediário Phyllocaulis 
variegatus (Semper, 1885), lesma de dilatada distribuição geográfica no continente sul-americano ${ }^{5,6}$, e outros moluscos, como Limax maximus (Linnaeus, 1758), L. flavus (Linnaeus, 1758) e B. similaris ${ }^{4}$.

A introdução de $A$. fulica no Brasil se deu visando ao cultivo e comercialização de "escargots", a partir de meados de 1988, conforme noticiado em diversas reportagens jornalísticas. Pelas razões apresentadas, a invasão ambiental pela espécie é preocupante, exigindo monitoramento, quer no sentido da preservação da saúde pública, como pelos

\section{REFERÊNCIAS BIBLIOGRÁFICAS}

1. AGUIAR, P. H.; MORERA, P.; PASCUAL, J. First record of Angiostrongylus cantonensis in Cuba. Am. J. Trop. Med. Hyg., 30: 963-5, 1981.

2. BENENSON, A. S., ed. El control de las enfermedades transmisibles en el hombre. Washington, D. C., Orgnización Panamericana de la Salud, 1978. (OPAS - Publ. Cient., 372).

3. GODAN, D. Pests slugs and snails. Berlin, Springer-Verlag, 1983.

4. GRAEFF-TEIXEIRA, C.; THIENGO, S. C.; THOMÉ, J. W.; MEDEIROS, A. L. B.; CAMILLO-COURA, L., AGOSTINI, A. A. On the diversity of mollusc intermediate hosts of Angiostrongylus costaricensis Moreira \& Cespedes, 1971 in southern Brazil. Mem. Inst. Oswaldo Cruz, 88: 487-9, 1993.

5. GRAEFF-TEIXEIRA, C.; CAMILLO-COURA, L., LENZI, H. L. Abdominal angiostrongyliasis - an under diagnosed disease. Mem. Inst. Oswaldo Cruz, 82: 353-4, 1987.

6. GRAEFF-TEIXEIRA, C.; THOMÉ, J. W.; PINTO, S. C. C.; CAMILLO-COURA, L., LENZI, H. L. Phylocaullis possíveis prejuízos que o molusco possa impor à agricultura. As informações obtidas no local de coleta dão conta de destruição da horta existente na escola, apesar da retirada diária de centenas de espécimes, demonstrando a provável adaptação do molusco às condições ecológicas da região em foco.

\section{AGRADECIMENTOS}

Ao sr. Júlio Colella, pelas informações sobre os relatos jornalísticos do cultivo de A. fulica no Brasil. variegatus - an intermediate host of Angiostrongylus costaricensis in South Brazil. Mem. Inst.Oswaldo Cruz, 90: 707-9, 1995.

7. MALEK, E. A. \& CHENG, T. C. Medical and economic malacology. New York. Academic Press, 1974.

8. MOTA, E. M. \& LENZI, H. L. Angiostrongylus costaricensis life cycle: a new proposal. Mem. Inst. Oswaldo Cruz, 90: 707-9, 1995.

9. NISHIMURA, K. \& SATO, Y. Natural infection with Angiostrongylus cantonensis in Ampullarius canaliculatus (Lamarck) in the Ryukyu Island, Japan. J. J. Parasitol., 35: 469-70, 1986.

10. WALLACE, G. D. \& ROSEN, L. Studies on eosinophilic meningites. V. Molluscan hosts of Angiostrongylus cantonensis on the Pacific Islands. Am. J. Trop. Med. Hyg., 18: 206-16, 1969.

11. WILSON, M. E. A world guide to infections: diseases, distribution, diagnosis. New York, Oxford University Press, 1991. 